\title{
BRIGHTNESS OF THE $\mathrm{O}_{2}$ ATMOSPHERIC BANDS IN THE DAYTIME THERMOSPHERE
}

\author{
W. R. SKINNER and P. B. HAYS \\ Department of Atmospheric and Oceanic Science, Space Physics Research I aboratory, \\ The University of Michigan, Ann Arbor, Michigan, U.S.A.
}

(Received 22 May 1984)

\begin{abstract}
The Fabry-Perot interferometer on Dynamics Explorer 2 was used as a low sensitivity photometer to study the $\mathrm{O}_{2}$ Atmospheric A band during the daytime. A study of the brightness of the emission showed that the assumed source of $\mathrm{O}_{2}\left(b^{1} \Sigma_{g}^{+}\right)$in the thermosphere, $\mathrm{O}\left({ }^{1} \mathrm{D}\right)$, can account for the observed intensity up to about $250 \mathrm{~km}$ but with a significantly different scale height. This combined with an enhanced brightness above this altitude suggests an additional source for this emission.
\end{abstract}

\section{INTRODUCTION}

An extensive sel of observational data exists for the emission of the $\mathrm{O}_{2}$ atmospheric bands $\left(b^{1} \Sigma_{g}^{+}-X^{3} \Sigma_{g}^{-}\right)$ under nighttime and auroral conditions. Reported studies of daytime observations, however, are limited to that of Wallace and Hunten (1968). They observed the $(0-0)$ and $(0-1)$ bands with rocket-borne photometers from approx. 40 to $130 \mathrm{~km}$, and concluded that above $100 \mathrm{~km}$ quenching of $\mathrm{O}\left({ }^{1} \mathrm{D}\right)$ by $\mathrm{O}_{2}$ is the predominant mechanism for the excitation of the $\mathrm{O}_{2}\left(b^{1} \Sigma_{g}^{+}\right)$state. Since their observations did not extend above $130 \mathrm{~km}$ this hypothesis could not be checked for the upper thermosphere. The Fabry-Perot interferometer on Dynamics Explorer 2 (DE-FPI) had a filter which transmitted the $\mathrm{A}$ band of the $\mathrm{O}_{2}$ atmospheric band system. The instrument allowed the daytime emission to be observed from the lowest observation tangent point $(\simeq 60 \mathrm{~km})$ to $300 \mathrm{~km}$. In this paper these data will be used to infer the brightness of the $\mathrm{O}_{2}$ bands on various occasions during the life of $D E-2$ (August 1981 to February 1983) and to confirm that $O\left({ }^{1} D\right)$ can account for the magnitude of the observed brightness of $\mathrm{O}_{2}\left(b^{1} \Sigma_{g}^{+}\right)$in the thermosphere up to about $250 \mathrm{~km}$, although the scale heights are considerably different. Above this altitude the observed brightness exceeds the calculated one. This paper will address these issues and consider the possibility of additional sources of $\mathrm{O}_{2}\left(b^{1} \Sigma_{q}^{+}\right)$in the thermosphere.

\section{MEASURED SURFACE BRIGHTNESS}

The Fabry-Perot interferometer on $D E-2$ has been discussed in some detail elsewhere (Hays et al., 1981; Killeen et al., 1982, 1983; Rees et al., 1982; Skinner, $1984)$ and only the most salient points are mentioned here and summarized in Table 1. The interferometer was a single etalon with solid spacers and had a $12-$ channel concentric ring detector which was used to scan in wavelength. A mirror system provided a limb scan consisting of 16 spectra. Depending on the satellite altitude and orientation the tangent point altitude ranged from roughly the satellite altitude to as low as 60 $\mathrm{km} . D E-2$ was in a polar orbit and data were taken at all latitudes and solar zenith angles. This analysis is limited to conditions with low magnetic latitudes and low solar zenith angle.

The $\mathrm{O}_{2}$ emission was studied by using the interferometer as a photometer. In order to relate the signal to the brightness it is necessary to consider the

Table 1. Characteristics OF DE-FPI aT $7650 \AA$

\begin{tabular}{ll}
\hline \multicolumn{1}{c}{ Parameter } & \multicolumn{1}{c}{ Value } \\
\hline Etalon gap & $1.2615 \mathrm{~cm}$ \\
Free spectral range (FSR) & $0.39536 \mathrm{~cm}^{-1}$ \\
& $0.2316 \AA$ \\
Number of channels per FSR & 12.36 \\
Fraction of FSR on detector & $97.1 \%$ \\
Spacing/channel & $0.032 \mathrm{~cm}^{-1}$ \\
& $0.019 \AA$ \\
Reflectivity & $62 \% @ 7650 \AA$ \\
Filter & $\mathrm{ZnS}-\mathrm{Cryolite}$ layers, \\
& single cavity, \\
& dielectric blocking to $5000 \AA$ \\
Peak position & $7668.3 \AA$ \\
Peak transmission & $63.5 \%$ \\
Halfwidth & $30.2 \AA$ \\
Detector & \\
anode structure & 12 concentric rings \\
photocathode & equal area anodes
\end{tabular}




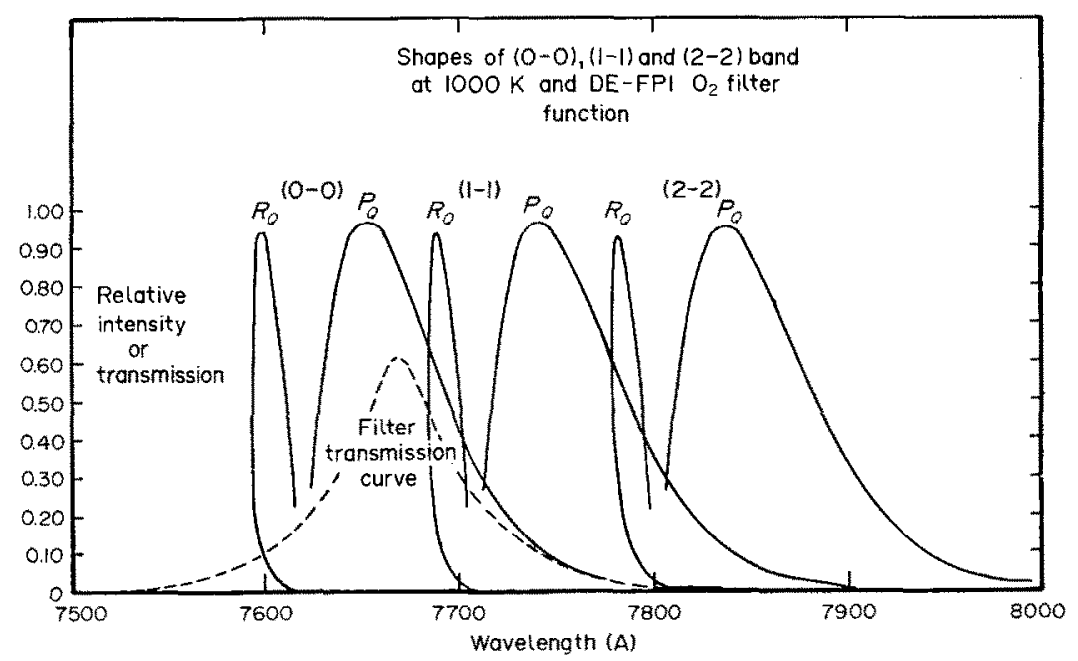

Fig. 1. TRANSMISSION FUNCTION OF DE-FPI $\mathrm{O}_{2}$ FILTER (DASHED LINE) AND THE ENVELOPE OF THE ROTA TIONAL INTENSITY DISIRIBUTION OF THE (0-0), (1-1), ANO (2-2) ATMOSPHERIC BANDS (SOLID LINES).

Only the envelopes for the ${ }^{\mathrm{R}} \mathrm{Q}$ and ${ }^{\mathrm{P}} \mathrm{Q}$ branches are shown but the $\mathrm{P}$ and $\mathrm{R}$ branches are very similar. The bands are shown with equal strength and with a temperature of $1000 \mathrm{~K}$.

vibrational transitions transmitted by the filter. Besides the (0-0) band for which the filter was designed, it can also transmit the (1-1) and (2-2) bands. Figure 1 shows the filter transmission curve and the line strength envelopes of the main branches of the $(0-0),(1-1),(2-2)$ bands. For purposes of illustration the bands are shown with the same intensity and reveals that the (1-1) band in particular can be significantly transmitted. The filter passes about $25 \%$ of the $(0-0)$ band, $20 \%$ of the (1-1), and $2 \%$ of the (2-2), with these values nearly independent of temperature. If the bands are in thermodynamic equilibrium then in a hot thermosphere $\left(T \simeq 1500^{\circ}\right)$ the (1-1) band can contribute up to $30 \%$ of the total signal while the (2-2) band will be insignificant. The atmospheric bands are so strong that it is unlikely that contaminant emission could compete in intensity. Because of the excess emission seen at high altitudes, however, the possibility of contaminant emission will be considered in the discussion section. The following data analysis assumes only the (0-0) and (1-1) bands are contributing to the signal.

The brightness of the $\mathrm{O}_{2}$ emission band can be estimated by using the $D E$-FPI as a photometer instead of an interferometer. A Fabry-Perot interferometer behaves as a photometer if the signal is summed over a free spectral range. The situation is slightly complicated in this case due to the large number of lines transmitted. The brightness from a series of lines, such as the $\mathrm{O}_{2}$ band, is just the summation of the brightness from each line (Skinner, 1984). The resulting signal from a given detector channel $k$ will be (Hays et al, 1981):

$$
\begin{aligned}
N_{k}= & C \Delta t\left(\frac{1-R}{1+K}\right) B \sum S_{J} T_{F}\left(v_{J}\right) \\
\cdot\left[a_{0 k}+\sum_{n=1}^{16} R^{n} \mathrm{e}^{-(\pi n G)^{2}}\right. & \left.\cdot\left[a_{n k} \cos \left(\frac{2 \pi n\left(v_{J}-v_{k}\right)}{\Delta v_{\mathrm{FSR}}}\right)+b_{n k} \sin \left(\frac{2 \pi n\left(v_{J}-v_{k}\right)}{\Delta v_{\mathrm{FSR}}}\right)\right]\right]
\end{aligned}
$$

where $k$ ranges from 1 to $12, C$ is the sensitivity, $\Delta t$ is the integration time, $B$ is the band brightness, $S_{J}$ is the normalized line strength of line $J, v_{J}$ is the position of line $J, T_{F}\left(v_{J}\right)$ is the filter transmission at $v_{J}, a_{n k}$ and $b_{n k}$ are the Fourier coefficients representing the instrument function, $\Delta v_{\mathrm{FSR}}$ is the free spectral range, $R$ is the reflectivity of the etalon plates, $v_{k}$ is the peak for detector channel $k$, and $G=\Delta v_{e} / \Delta v_{\mathrm{FSR}}$. All emission lines that have a significant intensity must be included in the sum. The molecular parameters needed to calculate the $\mathrm{O}_{2}$ atmospheric band line strengths and positions were obtained from Babcock and Herzberg (1948) and the Hönl-London factors were from Schlapp (1937).

The 12 detcctor channels comprise almost exactly one free spectral range and since the value of each Fourier component does not vary much from channel to channel, then if the signal from each channel is summed [equation (1)] all the Fourier terms vanish 
except for the zero order and the $\operatorname{sum}\left(N_{\text {sum }}\right)$ reduces to:

$$
\begin{aligned}
N_{\mathrm{sum}} & \sim C \Delta t\left(\frac{1-R}{1+R}\right) B \sum_{J} S_{J} T_{F}\left(v_{J}\right) \sum_{k} a_{0 k} \\
& =C^{\prime} B
\end{aligned}
$$

$C^{\prime}$ a constant. Simulations indicate that the wavelength dependent term

$$
\sum_{J} S_{J} T_{F}\left(v_{J}\right)
$$

equals 0.25 for the (0-0) band and 0.20 for the (1-1) band, independent of temperature. This combined with the fact that the Franck-Condon factors for the (0-0) and (1-1) bands are only $15 \%$ apart (Nicholls, 1965) means that it is not necessary to be concerned about the origin of the emission as long as it is from the (0-0) or the (1-1) band. All other calibration constants are known leading to a value for $C^{\prime}$ of about 0.003 counts per Rayleigh.

This estimated photometric sensitivity of the $D E$ FPI was used to provide the brightness of the $\mathrm{O}_{2}$ emission feature for approx. 10 orbits throughout the life of $D E-2$. Averaged data for individual orbits are plotted in Fig. 2 and show the horizontal line of sight brightness for high sun conditions (solar zenith angle less than $65^{\circ}$ ) and low magnetic latitude (magnetic latitude is less than $55^{\circ}$ ). The data show this emission to be extremely bright in the daytime theremosphere, with a line of sight brightness exceeding $10 \mathrm{kR}$ at $250 \mathrm{~km}$.

\section{THEORETICAL CALCULATION}

The brightness of the $\mathrm{O}_{2}\left(b^{1} \Sigma_{g}^{+}-X^{3} \Sigma_{g}^{-}\right)$emission as observed from the satellite was calculated assuming production from $\mathrm{O}\left({ }^{1} \mathrm{D}\right)$ and resonance scattering. Quenching of the $\mathrm{O}_{2}\left(b^{1} \Sigma_{g}^{+}\right)$state by $\mathrm{N}_{2}$ and $\mathrm{O}_{2}$ was included in the calculation but is negligible except at the lowest altitudes (Wallace and Hunten, 1968). At low altitudes the density of $O\left({ }^{1} \mathrm{D}\right)$ was calculated from the photolysis of $\mathrm{O}_{2}$. The density of $\mathrm{O}\left({ }^{1} \mathrm{D}\right)$ at higher altitudes was estimated using volume emission rates obtained from the Visible Airglow Experiment (VAE) on the Atmosphere Explorer ( $A E$ ) satellites (Hays et al., 1973). Two profiles were obtained, one from near solar minimum (Hays et al., 1978 and Torr et al., 1981) and another from $A E$-E near solar maximum in 1981 (V.J. Abreu, private communication, 1983). This latter profile was obtained using an inversion technique

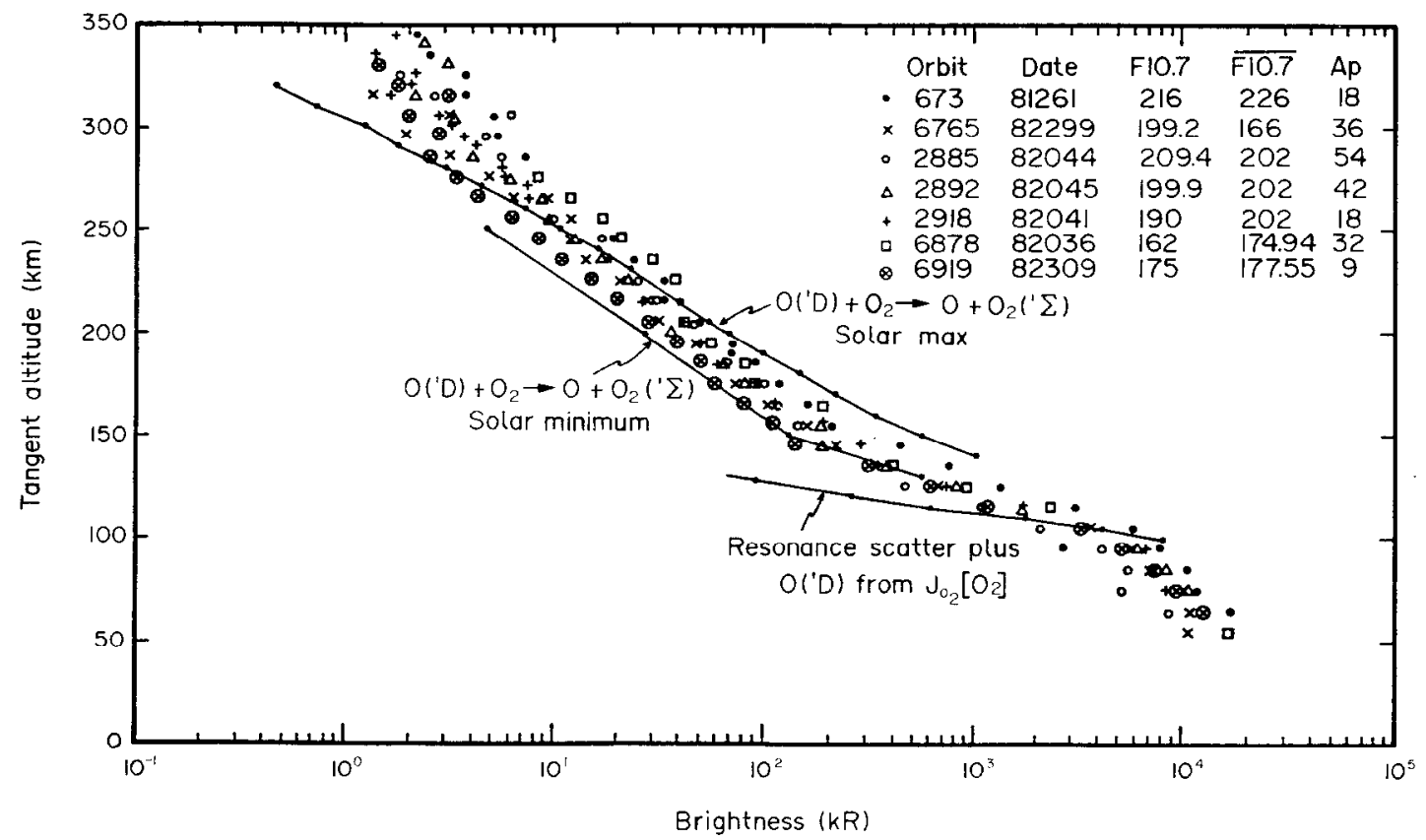

Fig. 2. Surface brightNess of THE $\mathrm{O}_{2}$ ATMOSPHERIC BANDS AS OBSER VED BY $D E-2$.

Data were taken for low magnetic latitude and low solar zenith angle conditions. Theoretically calculated brightnesses are also shown. The high altitude profiles were calculated from the quenching of $O\left({ }^{1} D\right)$. The $\mathrm{O}\left({ }^{1} \mathrm{D}\right)$ profiles were obtained from $A E$ data. The low altitude profile included resonance scattering and quenching of $\mathrm{O}\left({ }^{1} \mathrm{D}\right)$. Here $\mathrm{O}\left({ }^{1} \mathrm{D}\right)$ was calculated from photolysis of $\mathrm{O}_{2}$. 
VOLUME EMISSION RATE FOR $6300 \AA$ O('D)

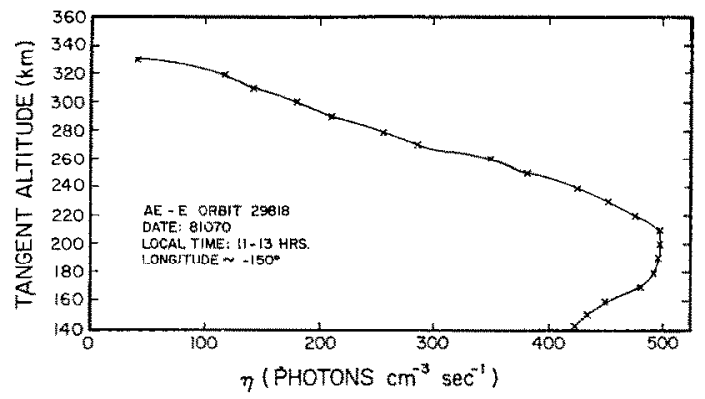

FIG. 3. $O\left({ }^{1} \mathrm{D}\right)$ RED I.INE VOLUME EMISSION RATE FOR $A E$-E ORBIT 29818.

This corresponds to near solar maximum.

described by Fesen and Hays (1982) and is shown in Fig. 3. The shape of this profile was confirmed by comparing with measurements of $6300 \AA$ emission laken by $D E$ FPI at the same time as the $\mathrm{O}_{2}$ emissions. The volume emission rates were converted to densities by using the Einstein coefficient value of $0.00515 \mathrm{~s}^{-1}$ given by Kernahan and Pang (1975).

The volume emission rate of $\mathrm{O}_{2}\left(b^{1} \Sigma_{g}^{+}\right)$in the thermosphere, where quenching is insignificant, is given by $k_{\mathrm{o}}\left[\mathrm{O}_{2}\right]\left[\mathrm{O}\left({ }^{1} \mathrm{D}\right)\right]$. The $\mathrm{O}_{2}$ densities were obtained from the MSIS-83 neutral atmosphere model (Hedin, 1983). Assuming the emission to be exponential in character the surface brightness will be (in Rayleighs):

$$
B=10^{-6} k_{\mathrm{o}}\left[\mathrm{O}_{2}\right]\left[\mathrm{O}\left({ }^{1} \mathrm{D}\right)\right] \sqrt{2 \pi\left(R_{e}+Z_{T}\right) H}
$$

with $k_{\mathrm{O}}=2.5 \times 10^{-11} \mathrm{~cm}^{3} \mathrm{~s}^{-1}$ (Link et al., 1981), $H$ the emission scale height, $Z_{T}$ the tangent point altitude and $R_{e}$ the radius of the Earth.

The results of the calculation are shown in Fig. 2 and the results at first appear encouraging. The calculated brightness at $200 \mathrm{~km}$ is $70 \mathrm{kR}$ which is in reasonable agreement with the observed average of $\simeq 50 \mathrm{kR}$. However, there are two distinct areas of disagreement. First, the scale heights of the profiles are considerably different. The calculated scale height of $\mathrm{O}_{2}\left(b^{1} \Sigma_{g}^{+}\right)$is a combination of the $\mathrm{O}\left({ }^{1} \mathrm{D}\right)$ and $\mathrm{O}_{2}$ scale heights. The scale height of the topside of the $O\left({ }^{1} \mathrm{D}\right)$ profile is found from the $D E$-FPI data to be $56 \mathrm{~km}$ above $240 \mathrm{~km}$. The $M S I S-83$ model gives an $\mathrm{O}_{2}$ scale height of $\simeq 36 \mathrm{~km}$ in the same region. This suggests that the emission profile should have roughly a scale height of $22 \mathrm{~km}$. The average scale height of the $\mathrm{O}_{2}\left(b^{\prime} \Sigma_{q}^{+}\right)$emission is much larger and close to the predicted $\mathrm{O}_{2}$ scale height, $37 \mathrm{~km}$. It would take a major change in the scale heights to obtain agreement. The $\mathrm{O}_{2}$ scale height in this region would need to be over $100 \mathrm{~km}$, while the $O\left({ }^{1} D\right)$ density would need to be nearly constant with height. Slightly lower, near the peak of the $\mathrm{O}\left({ }^{1} \mathrm{D}\right)$ density, the $\mathrm{O}_{2}$ emission scale height should be very close to the $\mathrm{O}_{2}$ scale height. In this instance the $\mathrm{O}\left({ }^{1} \mathrm{D}\right)$ peak is near 200 $\mathrm{km}$ and the MSIS $-83 \mathrm{O}_{2}$ seale height is $\simeq 28 \mathrm{~km}$. The actual emission scale height is still of the order of 35 $\mathrm{km}$, a difference of $25 \%$. The second problem concerns an excess of emission at high altitudes. The emission at $300 \mathrm{~km}$ is of the order of $3 \mathrm{kR}$ which is about a factor of 3 mote than is accounted for by the simple model. This discrepancy becomes increasingly worse at higher altitudes. This at first may appear to be a result of the smaller scale height of the calculated emission but a closer examination reveals the possibility thit the emission scale height is increasing above $300 \mathrm{~km}$.

\section{DISCUSSION}

Although the above arguments present strong evidence for another source of $\mathrm{O}_{2}\left(b^{1} \Sigma_{g}^{+}\right)$there are other alternatives that should be considered before a conclusion is reached. There is the possibility that the model atmosphere is not supplying reliable $\mathrm{O}_{2}$ densities. Since $\mathrm{O}_{2}$ is difficult to measure at these altitudes this alternative cannot be eliminated. As noted above the scale height of $\mathrm{O}_{2}$ would have to be increased an unrealistic amount to obtain agreement.

Onc should also consider the possibility that emissions due to sources other than $\mathrm{O}_{2}$ may be responsible for the additional signal. Since the filter was about $60 \AA$ wide there are several candidates. One possible source of contamination is the background continuum usually thought to be due to the chemiluminescence reaction $\mathrm{NO}+\mathrm{O} \rightarrow \mathrm{NO}_{2}+h v$. At night this process forms a layer near the height of the $\mathrm{O}_{2}$ atmospheric bands and has a value of roughly $1 R A^{-1}$ (Gadsden and Marovich, 1973). It would take an unrealistic enhancement during the day for this emission to be important to this measurement. For example, at $200 \mathrm{~km}$ the line of sight brightness of $\mathrm{O}_{2}$ is about $60 \mathrm{kR}$. To be equal in intensity a continuum would have to be $\simeq 1 \mathrm{kR} \AA^{-1}$. At $100 \mathrm{~km}$ the band brightness rises to about $5000 \mathrm{kR}$ and the background would need to be $\simeq 85 \mathrm{kR} \AA^{-1}$. These are clearly unrealistic and the background continuum can safely be ignored during the day.

The OH Meinel (9-4) band at $7748 \AA$ can also be transmitted by the filter. $\mathrm{OH}$ emissions are usually considered mesospheric sources and should be unimportant at higher altitudes. The $\mathrm{N}_{2}$ first positive bands are also a possibility. The $(2-0)$ band at $\simeq 7754 \AA$ and the (3-1) band at $\simeq 7627 \AA$ (Vallance Jones and Gattinger, 1972) can both be transmitted to some extent. The total first positive band has an estimated 
daytime vertical brightness of 6.6-28 kR (Feldman, 1972; Green and Barth, 1967) and the fraction in the $(2-0)$ and (3-1) bands is probably much smaller than this. The $\mathrm{O}_{2} \mathrm{~A}$ band brightness during the day has an integrated vertical brightness of several hundred $k R$ which means that unless the $\mathrm{N}_{2}$ first positive band is emitted from high altitudes, it cannot compete with the $\mathrm{O}_{2}$ emission.

One explanation for the additional emission might be direct excitation by photoelectrons $\mathrm{O}_{2}+e$ $\rightarrow \mathrm{O}_{2}\left(b^{1} \Sigma_{q}^{+}\right)+e$. This source can be estimated by the ratio of the production of $\mathrm{O}\left({ }^{1} \mathrm{D}\right)$ and $\mathrm{O}_{2}\left(b^{1} \Sigma_{g}^{+}\right)$by electrons :

$$
\begin{aligned}
\frac{P\left(\mathrm{O}_{2}\left(b^{1} \Sigma_{g}^{+}\right)\right)}{P\left(\mathrm{O}\left({ }^{1} \mathrm{D}\right)\right)} & =\frac{k_{\mathrm{O}_{2}} n_{e}\left[\mathrm{O}_{2}\right]}{k_{\mathrm{O}} n_{e}[\mathrm{O}]} \\
& =\frac{k_{\mathrm{O}_{2}}\left[\mathrm{O}_{2}\right]}{k_{\mathrm{o}}[\mathrm{O}]}
\end{aligned}
$$

where $n_{e}$ is the density of electrons, $k_{\mathrm{O}_{2}}$ and $k_{\mathrm{O}}$ are unimolecular rate constants (Hays et al., 1978). By referring to the cross sections for $\mathrm{O}$ and $\mathrm{O}_{2}$ in Oran and Strickland (1976) a rough estimate for $k_{\mathrm{O}_{2}} / k_{\mathrm{O}}$ is 0.1 . At $300 \mathrm{~km}$ the density of $O$ is about $1.2 \times 10^{9} \mathrm{~cm}^{-3}$, that of $\mathrm{O}_{2}$ about $1.2 \times 10^{7} \mathrm{~cm}^{-3}$ giving $\mathrm{P}\left(\mathrm{O}_{2}\left(b^{1} \Sigma_{g}^{+}\right)\right) / \mathrm{P}\left(\mathrm{O}\left({ }^{1} \mathrm{D}\right)\right)$ $\simeq 10^{-3}$. The production of $O\left({ }^{1} \mathrm{D}\right)$ for the conditions of interest is about $2.8 \times 10^{3} \mathrm{~cm}^{3} \mathrm{~s}^{-1}$ and $\mathrm{P}\left(\mathrm{O}_{2}\left(b^{1} \Sigma_{g}^{+}\right)\right)$ $\simeq 2.8 \mathrm{~cm}^{3} \mathrm{~s}^{-1}$. This mechanism falls more than an order of magnitude short of what is required.

Another scheme is a reaction with atmospheric metastables. The two that dominate at this altitude are $\mathrm{O}\left({ }^{1} \mathrm{D}\right)$ and $\mathrm{N}\left({ }^{2} \mathrm{D}\right)$. No other species would appear to have the density required to produce the emission. Vallance Jones and Gattinger (1974) have speculated that the rate constant for the reaction

$$
\mathrm{N}\left({ }^{2} \mathrm{D}\right)+\mathrm{O}_{2} \rightarrow \mathrm{N}+\mathrm{O}_{2}\left(b^{1} \Sigma_{g}^{+}\right)
$$

may be $\simeq 1 \times 10^{-12} \mathrm{~cm}^{3} \mathrm{~s}^{-1}$. This reaction must compete with

$$
\mathrm{N}\left({ }^{2} \mathrm{D}\right)+\mathrm{O}_{2} \rightarrow \mathrm{NO}+\mathrm{O}
$$

which has a rate of $\simeq 1 \times 10^{-11} \mathrm{~cm}^{3} \mathrm{~s}^{-1}$ (Vallance Jones and Gattinger, 1974). This rate constant requires a density of $4 \times 10^{6} \mathrm{~cm}^{-3}$ at $300 \mathrm{~km}$ to make this process work. This would be several times higher than the $1 \times 10^{5} \mathrm{~cm}^{-3}$ given as typical by Torr and Torr (1982). The typical density would require a rate of $4 \times 10^{-11}$ $\mathrm{cm}^{3} \mathrm{~s}^{-1}$. However, this would give about twice the $\mathrm{O}_{2}\left(b^{1} \Sigma_{g}^{+}\right)$density at $200 \mathrm{~km}$, which would destroy the good agreement between theory and measurements there. Unless the number densities of $\mathrm{N}\left({ }^{2} \mathrm{D}\right)$ at around $300 \mathrm{~km}$ are considerably enhanced near solar maximum, this cannot provide the additional source.

Another avenue is the possibility of some sort of ionneutral interaction. This usually takes the form of a charge exchange but perhaps some fraction may excite $\mathrm{O}_{2}\left(b^{1} \Sigma_{g}^{+}\right)$. The main ionic species at these altitudes is $\mathrm{O}^{+}$which can appear in two forms that can transfer energy to $\mathrm{O}_{2}, \mathrm{O}^{+}\left({ }^{2} \mathrm{P}\right)$ and $\mathrm{O}^{+}\left({ }^{2} \mathrm{D}\right)$. The transition $\mathrm{O}^{+}\left({ }^{2} \mathrm{P}_{-}{ }^{2} \mathrm{D}\right)$ emits a photon with an energy of $1.69 \mathrm{eV}$ $(7320 \AA)$ making it only $0.07 \mathrm{eV}$ out of resonance with the (0-0) transition of $\mathrm{O}_{2}(7620 \AA)$. However, the number density of $\mathrm{O}^{+}\left({ }^{2} \mathrm{P}\right)$ at $300 \mathrm{~km}$ is only $250-300$ $\mathrm{cm}^{-3}$ which would require a rate coefficient of $\simeq 1.4$ $\times 10^{-8} \mathrm{~cm}^{3} \mathrm{~s}^{-1} . \mathrm{O}^{+}\left({ }^{2} \mathrm{D}\right)$ has a density an order of magnitude higher and requires a rate $\simeq 2 \times 10^{-9} \mathrm{~cm}^{3}$ $\mathrm{s}^{-1}$. The charge exchange between $\mathrm{O}^{+}\left({ }^{2} \mathrm{D}\right)$ and $\mathrm{O}_{2}$ has been estimated to be $\simeq 1 \times 10^{-9} \mathrm{~cm}^{3} \mathrm{~s}^{-1}$ [Torr and Torr (1982)]. The rate for production of $\mathrm{O}_{2}\left(h^{1} \Sigma_{g}^{+}\right)$by this process seems to require a rate coefficient larger than that for charge exchange which is unlikely for this type of reaction. The emission of $\mathrm{O}_{2}\left(b^{1} \Sigma_{g}^{+}\right)$at high altitudes cannot be adequately explained by the processes described here.

\section{SUMMARY}

The (0-0) and (1-1) bands of the $\mathrm{O}_{2}$ atmospheric system were observed with the Fabry-Perot interferometer on the $D E-2$ satellite. The band brightness was estimated by using the instrument as a low sensitivity photometer. The observed brightness was found to be in accord with commonly accepted theory for the production of $\mathrm{O}_{2}\left(b^{1} \Sigma_{g}^{+}\right)$, which is energy transfer of $\mathrm{O}\left({ }^{1} \mathrm{D}\right)$ between 140 and $250 \mathrm{~km}$. However, the scale height is significantly different. Above $250 \mathrm{~km}$ the theory and measurements become increasingly dissimilar. This suggests an additional source is needed for the $\mathrm{O}_{2}$ atmospheric band cmission, one which becomes increasingly important at higher altitudes. The mechanism has not been identified in the work.

Acknowledgernents - The authors wish to acknowledge the aid of V. J. Abreu and T. L. Killeen. This work was supported by NASA grant NAS5-15691 to The University of Michigan.

\section{REFERENCES}

Babcock, H. D. and Herzberg, L. (1948) Fine structure of the red system of atmospheric oxygen bands. Astrophys. J.108, 167.

Feldman, P.D.(1972) Resonance scattering of the first positive system of $\mathrm{N}_{2}$ in the dayglow. Planet. Space Sci. 20, 549.

Fesen, C. R. and Hays, P. B.(1982) Two-dimensional inversion technique for satellite airglow data. Appl. Opt. 21, 3784.

Gadsden, M. and Marovich, E. (1973) The nightglow continuum. J. atmos. terr. Phys. 35, 1601.

Green, A. E. S. and Barth, C. A. (1967) Calculations of the photoelectron excitation of the dayglow. J.geophys. Res. 72 . 3975 .

Hays, P. B., Carignan, G. R., Kennedy, B. C., Sheperd, G. G. and Walker, J. C. G. (1973) The visible-airglow experiment on Atmosphere Explorer. Radio Sci. 8, 369.

Hays, P. B., Rusch, D. W., Roble, R. G. and Walker, J. C. G. 
(1978) The O I (6300 §) Airglow. Rev. Geophys. Space Phys. $16,225$.

Hays, P. B., Killeen, T. L. and Kennedy, B. C. (1981) The Fabry-Perot interferometer on Dynamics Explorer. Space Sci. Inst. 5, 395.

Hedin, A. E. (1983) A revised global thermospheric model based on mass spectrometer and incoherent scatter data MSIS-1983. J. geophys. Res. 88, 10170.

Kernahan, J. A. and Pang, P. H.-L. (1975) Experimental determination of absolute A coefficients for 'forbidden' atomic oxygen lines. Can. J. Phys. 53, 455.

Killeen, T. L., Hays, P. B., Kennedy, B. C. and Rees, D. (1982) Stable and rugged etalon for the Dynamics Explorer FabryPerot interferometer. 2: Performance. Appl. Opt. 21, 3903.

Killeen, T. L., Kennedy, B. C., Hays, P. B., Symanow, D. A. and Ceckowski, D. H. (1983) An image plane detector for the Fabry-Perot interferometer on Dynamics Explorer. Appl. Opt. 22, 3503.

Link, R., McConnell, J. C. and Sheperd, G. G. (1981) A selfconsistent evaluation of the rate constants for the production of the OI6300 A airglow. Planet. Space Sci. 29, 589.

Nicholls, R. W. (1965) Franck-Condon factors to high vibrational quantum numbers $\mathrm{V}: \mathrm{O}_{2}$ band systems. J. Res. NBS 69A, 369.

Oran, E. S. and Strickland, D. J. (1976) Calculation of the ionospheric photoelectron distribution function. NRC memorandum report number 3361.

Rees, D., Fuller-Rowell, T. J., Lyons, A., Killeen, T. L. and Hays, P. B. (1982) Stable and rugged etalon for the Dynamics Explorer Fabry-Perot interferometer. 1 : Design and construction. Appl. Opt. 21, 3896.

Schlapp, R. (1937) Fine structure in the $X^{3} \Sigma_{g}^{-}$ground state of the oxygen molecule, and the rotational intensity distribution in the atmospheric oxygen band. Phys. Rev. 51, 342.

Skinner, W. R. (1984) Ph.D. thesis, The University of Michigan.

Torr, D. G., Richards, P. G., Torr, M. R. and Abreu, V.J.(1981) Further quantification of the sources and sinks of thermospheric $\mathrm{O}\left({ }^{1} \mathrm{D}\right)$ atoms. Planet Space Sci. 29, 595.

Torr, M. R. and Torr, D. G. (1982) The role of metastable species in the thermosphere. Rev. Geophys. Space Phys. 20, 91.

Vallance Jones, A. and Gattinger, R. L. (1972) Quantitative spectroscopy of the aurora. I. The spectrum of bright aurora between 7000 and $9000 \AA \AA$ at $7.5 \AA$ resolution. Can.J. Phys. 50, 1833.

Vallance Jones, A. (1974) The $\mathrm{O}_{2}\left(b^{1} \Sigma_{g}^{+}\right)-\left(X^{3} \Sigma_{g}^{-}\right)$system in Aurora. J. geophys. Res. 79, 4821.

Wallace, L. and Hunten, D. M. (1968) Dayglow of the oxygen A band. J. geophys. Res. 73, 4813. 